ES/ER/TM-61

\title{
Environmental Restoration Program Pollution Prevention Performance Measures for FY 1993 and 1994 Remedial Investigations: Management Training Manual
}

Environmental Restoration Program

P.O. Box 2003

Oak Ridge, Tennessee 37831-7298

Date Issued-March 1993

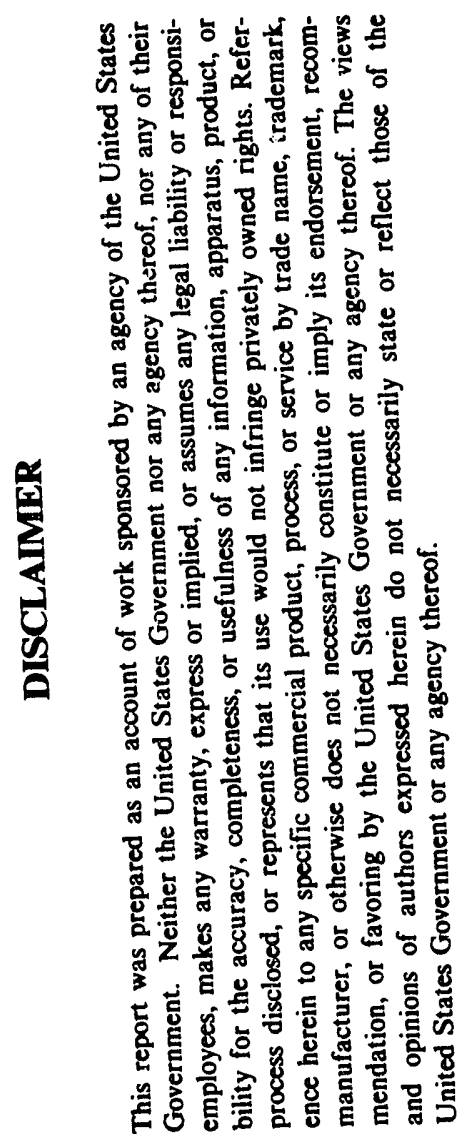

\author{
Prepared for \\ U.S. Department of Energy \\ Office of Environmental Restoration and Waste Management \\ under budget and reporting code EW 20
}

MARTIN MARIETTA ENERGY SYSTEMS, INC. managing the

Oak Ridge K-25 Site

Oak Ridge Y-12 Plant

Oak Ridge National Laboratory under contract DE-AC05-84OR21400
Paducah Gaseous Diffusion Plant Portsmouth Gaseous Diffusion Plant under contract DE-AC05-76OR00001 


\section{Numerical Scoring System}

Created for: Martin Marietta Energy Systems, Inc.

Created by: Roy F. Weston, Inc.

\section{Welcome to the NSS}

his computer-based program is designed to help waste generators in the Environmental Restoration (ER) Program prevent pollution at the DOE Oak Ridge Field Office (DOE-OR) facilities in Oak Ridge, Paducah, and Portsmouth. The Numerical Scoring System (NSS) is an interactive system designed to maintain data on ER Program pollution prevention efforts and to measure the success of these efforts through the ER Program life cycle. At any time, if you have questions about this program, please contact Bernard Phifer, at 615-576-4020.

The questionnaires in the NSS are divided into three sections. The first section consists of general questions which apply to every phase of the program. These questions were developed from the combination of the required elements in the pollution prevention program and the elements of NQA-1 that are related to waste minimization. The second is the phase-specific section. The questions were developed from the common elements which apply to each ER phase. The third section is the set of questions developed from waste reduction techniques based on different types of waste streams and is designed specifically for the remedial investigation phase.
The back cover of your Numerical Scoring System Training Manual should contain a diskette (pictured below) with a copy of the NSS program. Installation instructions are provided on page 2 .

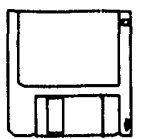

\section{Hardware Requirements}

The following equipment is required in order to install and run the software

- NSS Program software (located at back of manual)

- IBM (or compatible) PC

- Hard drive with at least 1.6 MB of available space

- 4 MB RAM
Call your central pollution prevention specialist (Bernard Phifer) at 615-576-4020 for help. 


\section{Installation Instructions}

To install the software, follow the steps below, typing the bolded commands at your DOS prompt:

Create a directory on your hard drive named "NSS."

$c:>$ cdl

c: $>$ md nss

Change to the newly created directory and install the software.

c: $>$ cdlnss

c: > a:nss

The software should be successfully installed on your hard drive at this point.

\section{Startup of Software}

Change to the NSS directory and start the program.

c: $>$ cd $\backslash$ nss

$c:>$ erwm

The following pages of this Management Training Manual contain pictures of screens that will appear when you run the NSS Program and a brief description of each screen.

Call your central pollution

prevention specialist

(Bernard Phifer) at

615-576-4020 for help. 


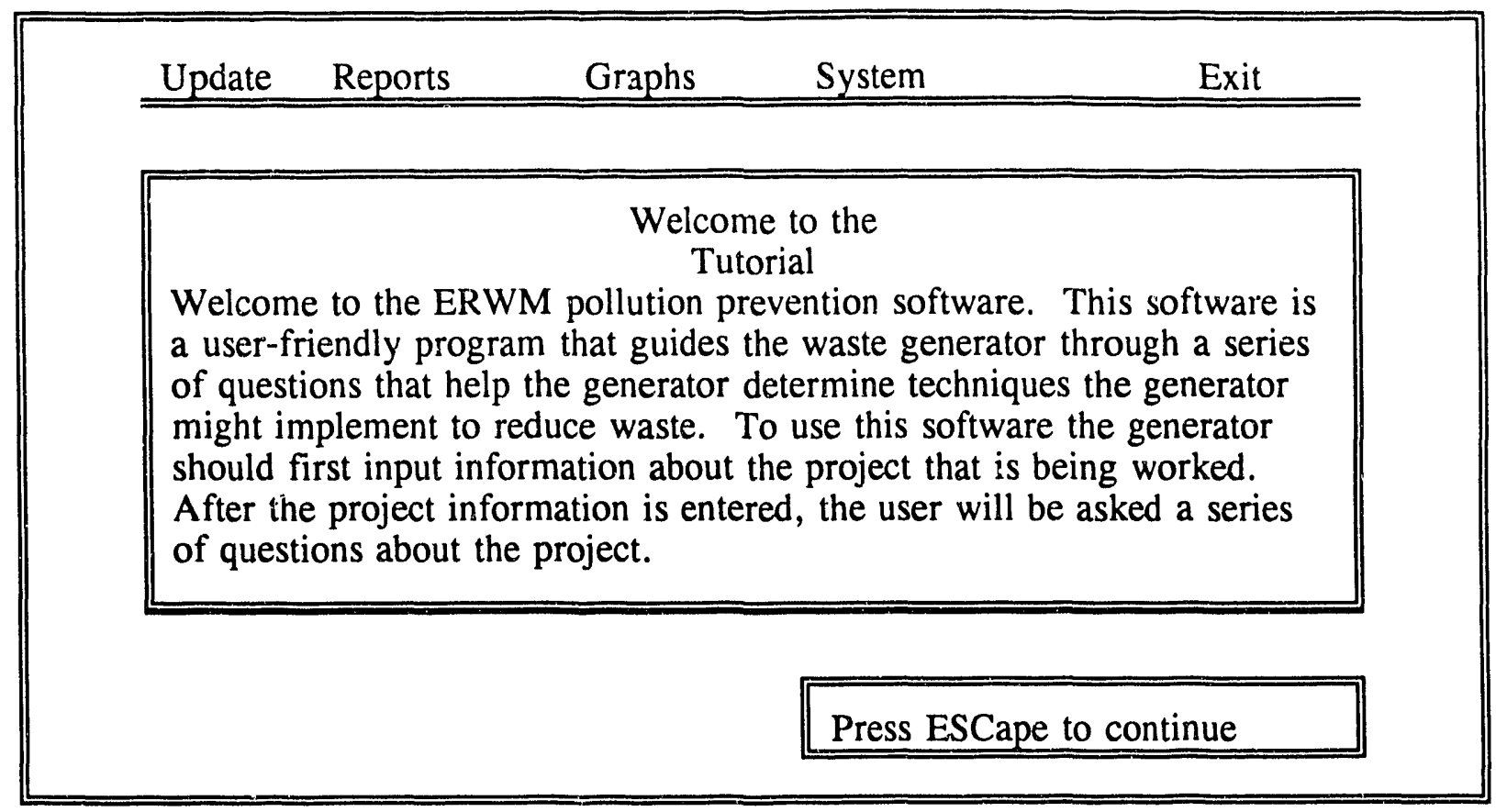

This is the opening screen that appears once the NSS Program has been initiated. A tutorial is provided in case additional information is needed to use the NSS. The user accesses the NSS by the ESCape key. 


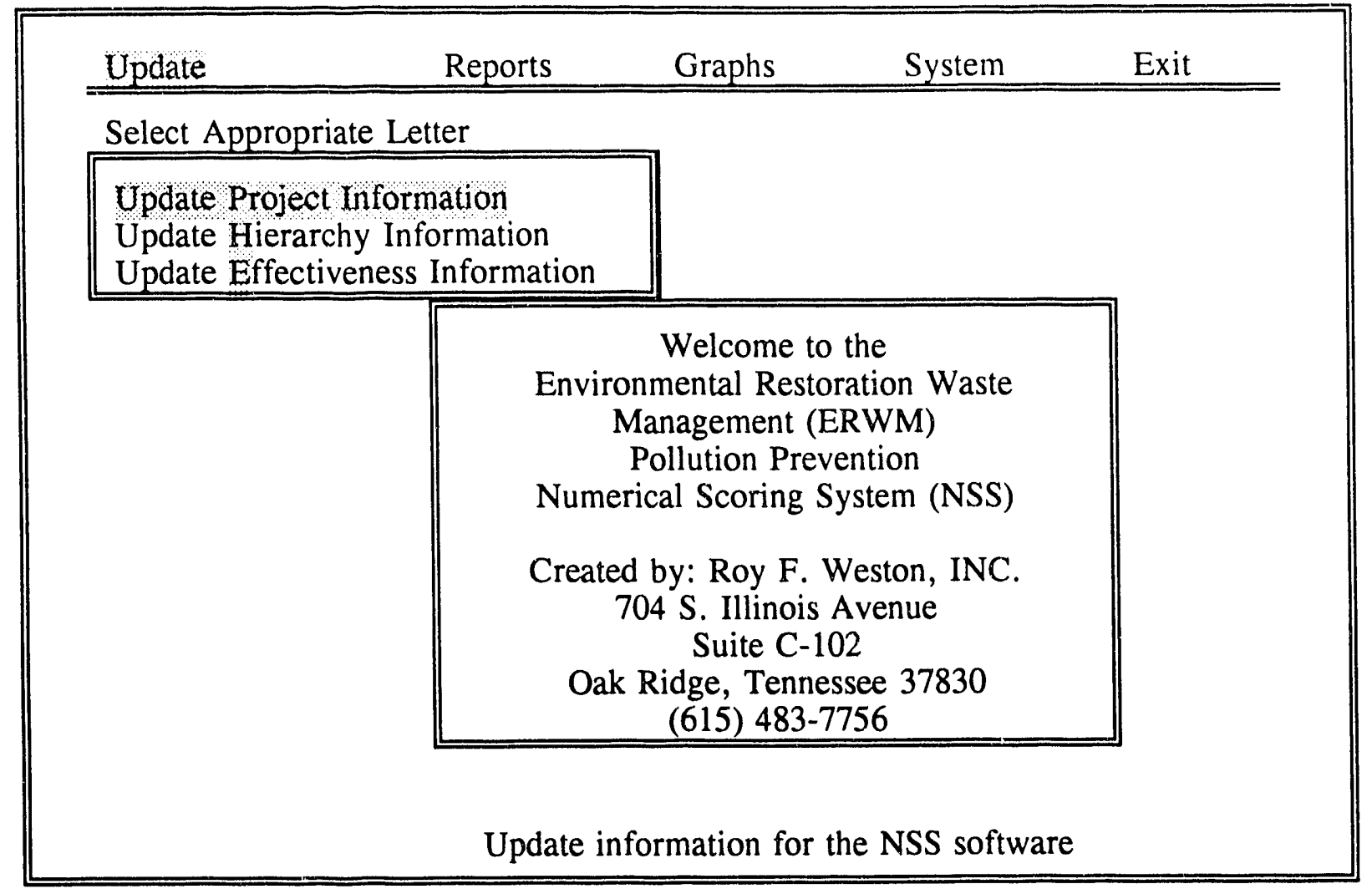

This is the main menu screen. The main menu consists of five (5) choices: update, reports, graphs, system, and exit. The update choice allows the user to update the project information, the hierarchy information, and the effectiveness information. The reports menu consists of ten (10) categories from which the user can get information. These categories are the NSS score report, the list of project answers, the list of phase answers, the list of waste stream answers, the types of waste, the list of the waste stream effectiveness, the hierarchy information, the waste volume information, answer analysis, and all NSS scores. The graphs menu lets the user choose to print graphs for the individual questions and for the overall question information. The system option has five (5) choices for the user. The user can back up the database, restore the database to its original structure, provide the scoring information, turn the introductory screen on or off, and access the tutorial. The last choice available to the user from the main menu is to exit the NSS program. 


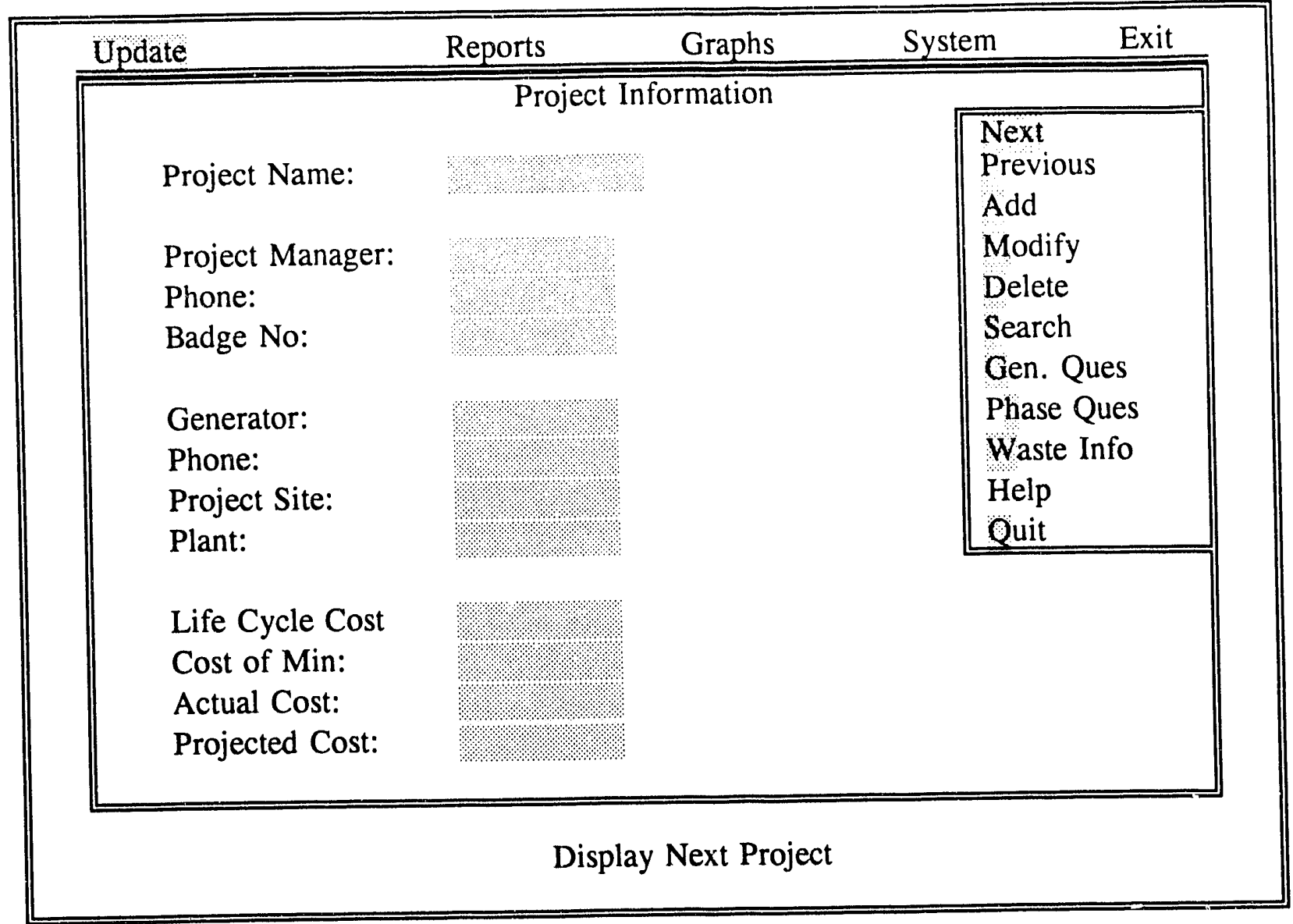

The above screen is presented in the NSS when the user chooses to "Update Project Information." Using the menu on the right of the screen, the user can scroll forward through the different projects by choosing "Next" or scroll backward by choosing "Previous." The user can also search through the list of projects using the "Search" command. From this menu, the user can change information in an existing project with the "Modify" command and remove existing projects using the "Delete" command. The user can also supplement the database with another project by using the "Add" command. Once the project has been identified and is on the screen, the user can review, modify, or answer the three sets of questions. The generator questions are accessed with the "Gen. Ques" command, the phase questions are accessed with the "Phase Ques" command, and the waste stream questions are accessed with the "Waste Info" command. If the user has any problems with the choices, on-line assistance is available using the "Help" command. The user can return to the main menu with the "Quit" command.

To "Add" a new project, the user provides the information at the left side of the screen. 


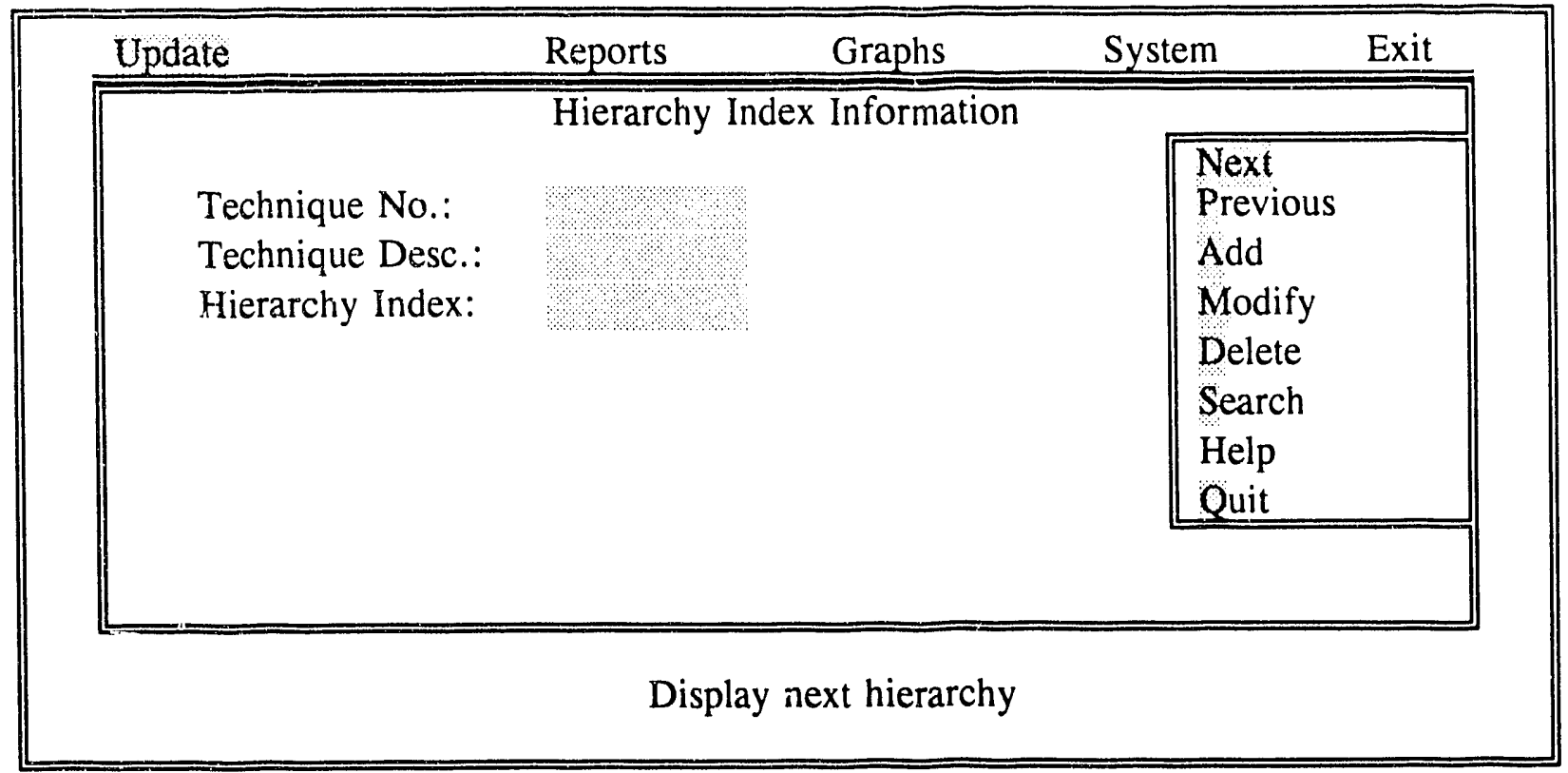

The above screen is presented in the NSS when the user chooses to "Update Hierarchy Information." Using the menu on the right of the screen, the user can scroll forward through the different indexes by choosing "Next" or scroll backward by choosing "Previous." The user can also search through the entire list of hierarchies using the "Search" command. From this menu, the user can change the hierarchy index with the "Modify" command and remove existing hierarchies with the "Delete" command. The user can also supplement the database with another hierarchy index by using the "Add" command. If the user has any problems with the choices, on-line assistance is available by using the "Help" command. The user can return to the main menu with the "Quit" command.

To "Add" a new hierarchy index, the user provides the information located on the left side of the screen. 


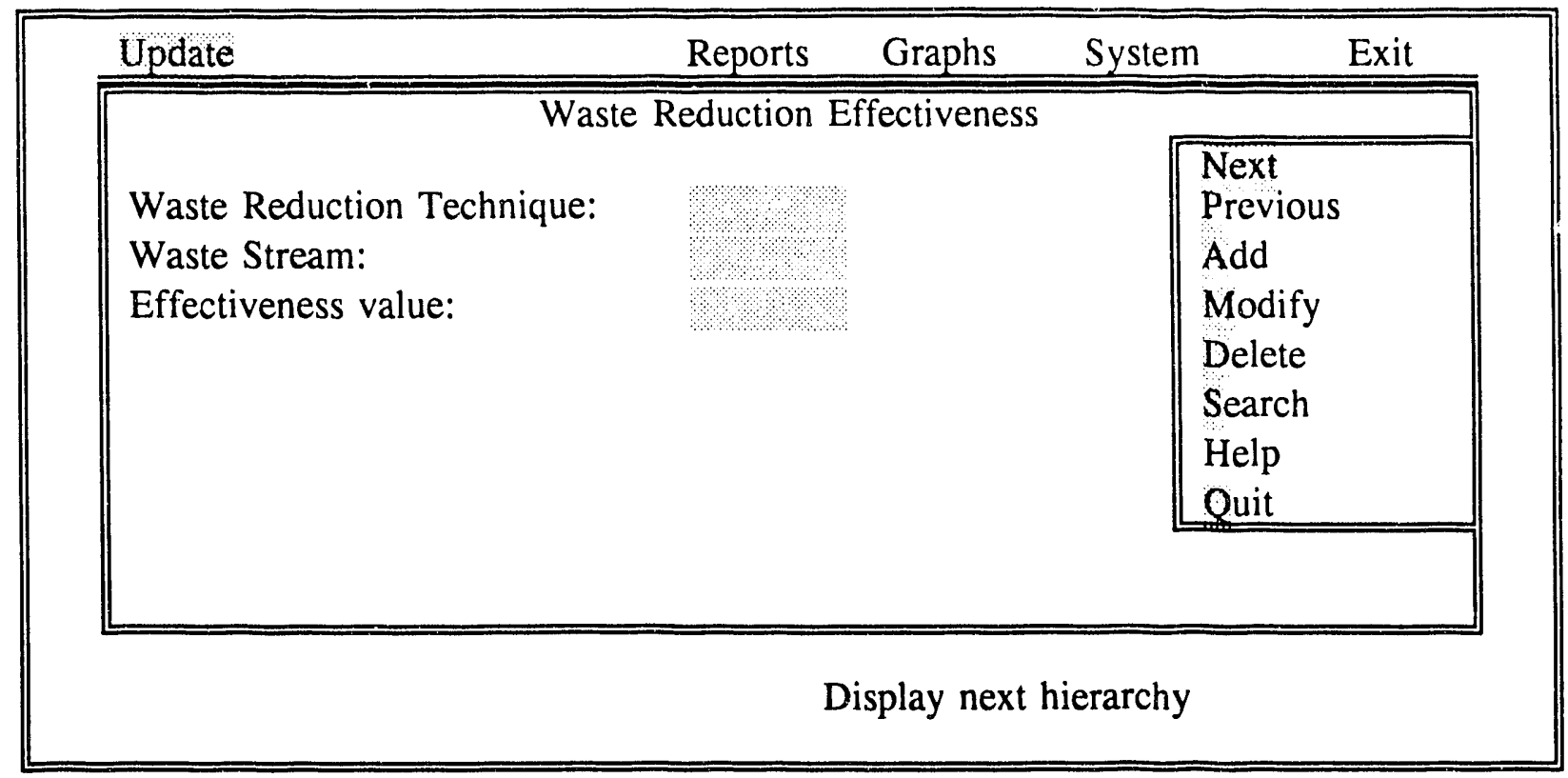

The above screen is presented in the NSS when the user chooses to "Update Effectiveness Information." Using the menu on the right of the screen, the user can scroll forward through the different indexes by choosing "Next" or scroll backward by choosing "Previous." The user can also search through the entire list of effectiveness for waste reduction techniques using the "Search" command. From this menu, the user can change the effectiveness with the "Modify" command and remove the effectiveness technique with the "Delete" command. The user can also supplement the database with the "Add" command. If the user has any problems with the choices, on-line assistance is available by using the "Help" command. The user can return to the main menu with the "Quit" command.

To "Add" a new waste reduction technique effectiveness, the user provides the information located on the left side of the screen. 


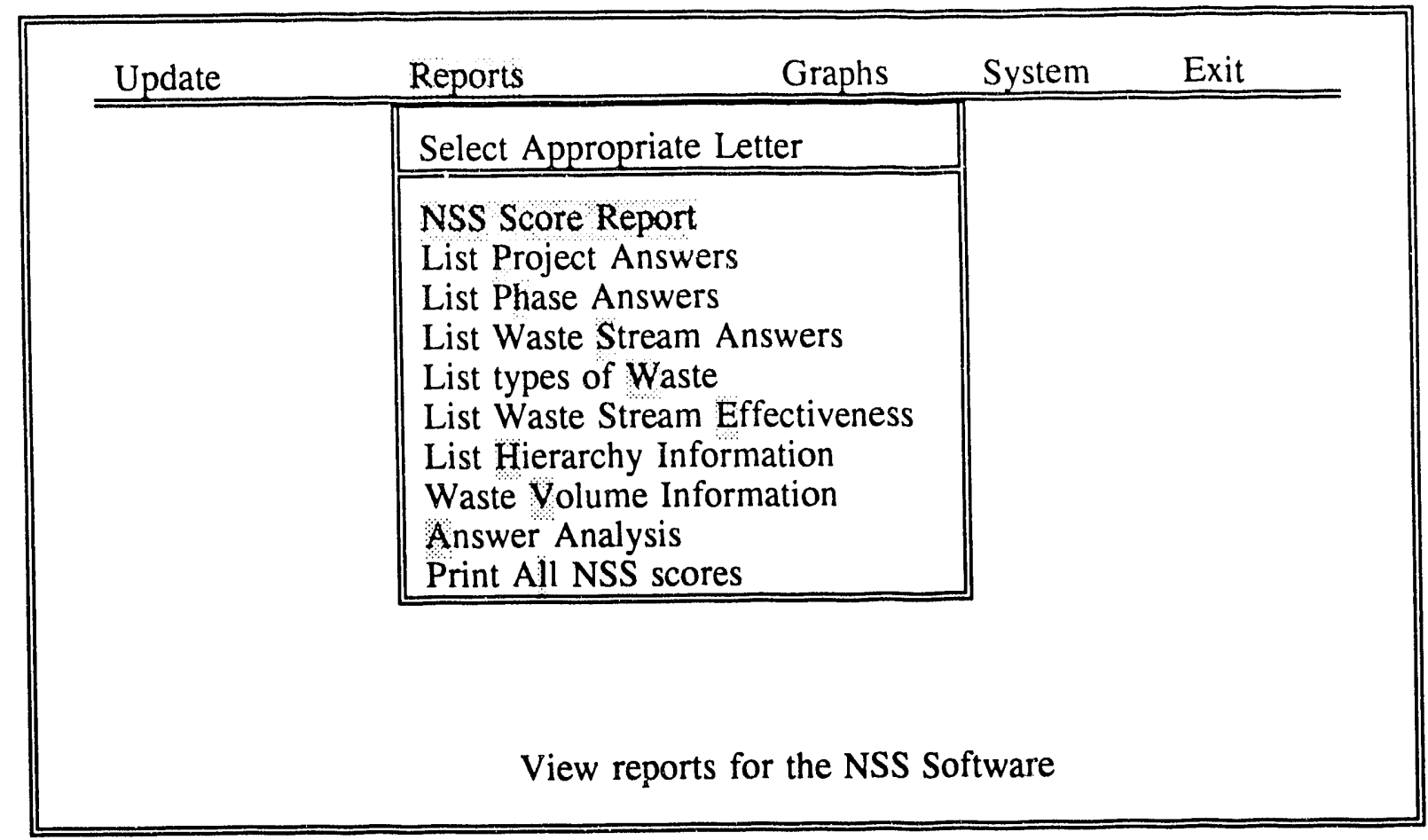

The above screen lists the different reports available to the user. The reports menu consists of ten (10) different categories of information that the NSS can provide for the user. The user can choose to see the NSS score report by performance section or plant and can see the report on the scresn, send it to the printer, or file it. The screen for this choice is presented on the next page.

The user can see the answers by project for the project questions, the phase questions, and the waste stream questions by choosing the appropriate category, "List Project Answers," "List Phase Answers," and "List Waste Stream Answers," respectively.

Additional information that can be obtained from this screen are the types of waste, the waste stream effectiveness, the hierarchy information, the waste volume information, answer analysis, and all NSS scores. 


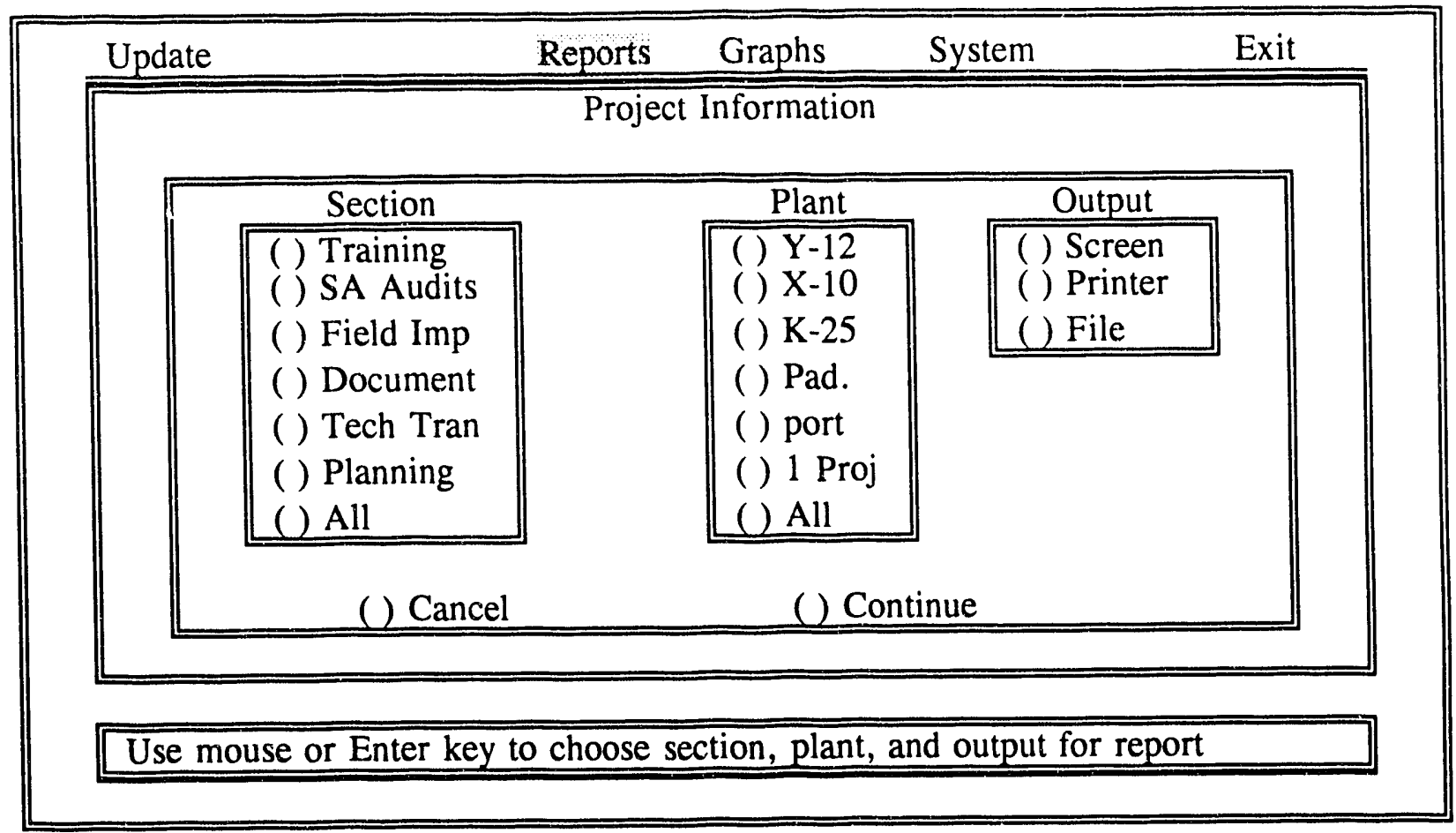

If the user chooses "NSS Score Report" from the previous screen, this screen is displayed. At this point, the user can select the categories of interest to be displayed and the output destination. "Cancel" returns the user to the NSS main menu. "Continue" allows the user to select the project of interest; the score is reported in the format below.

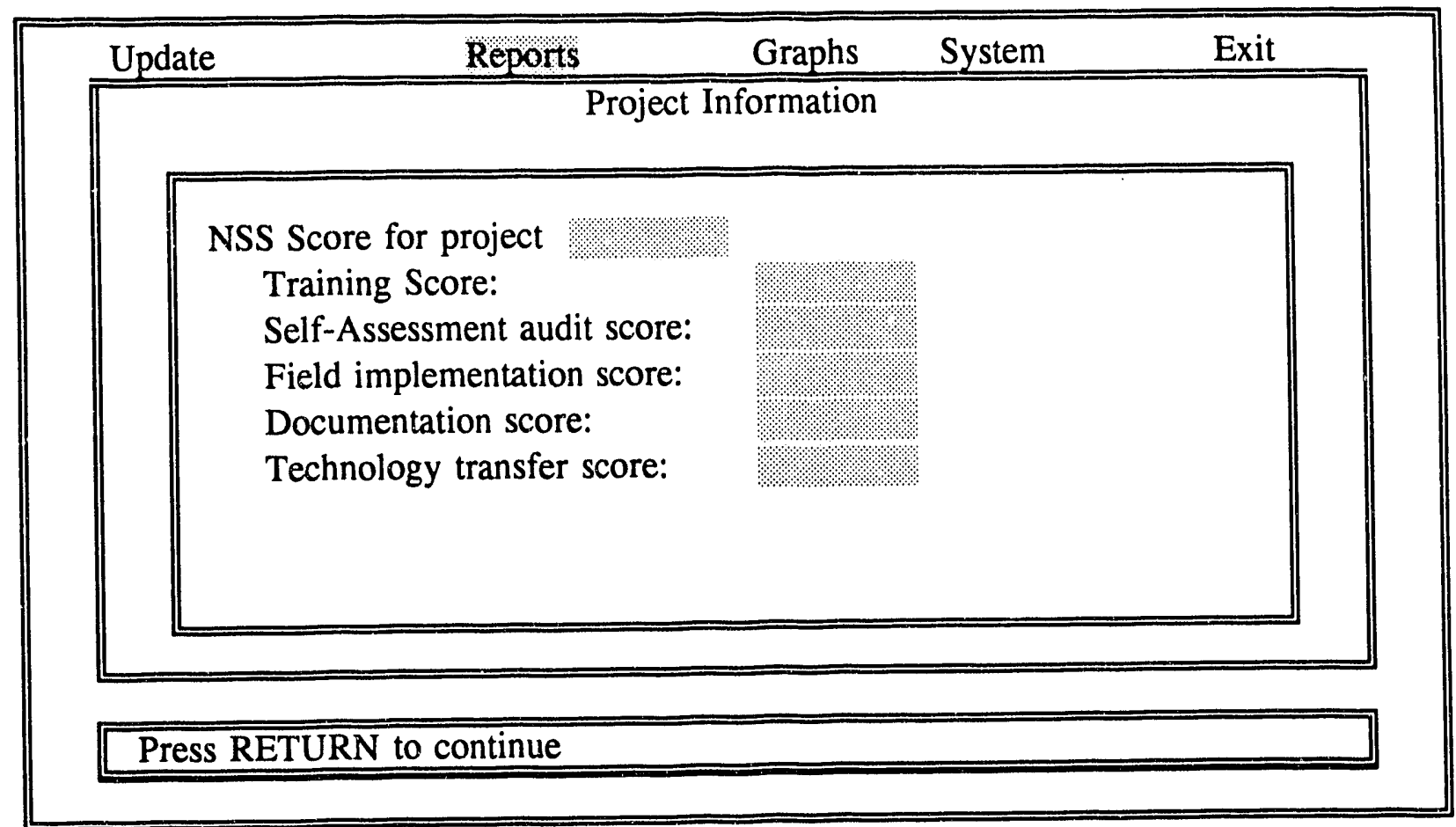

axpas: 


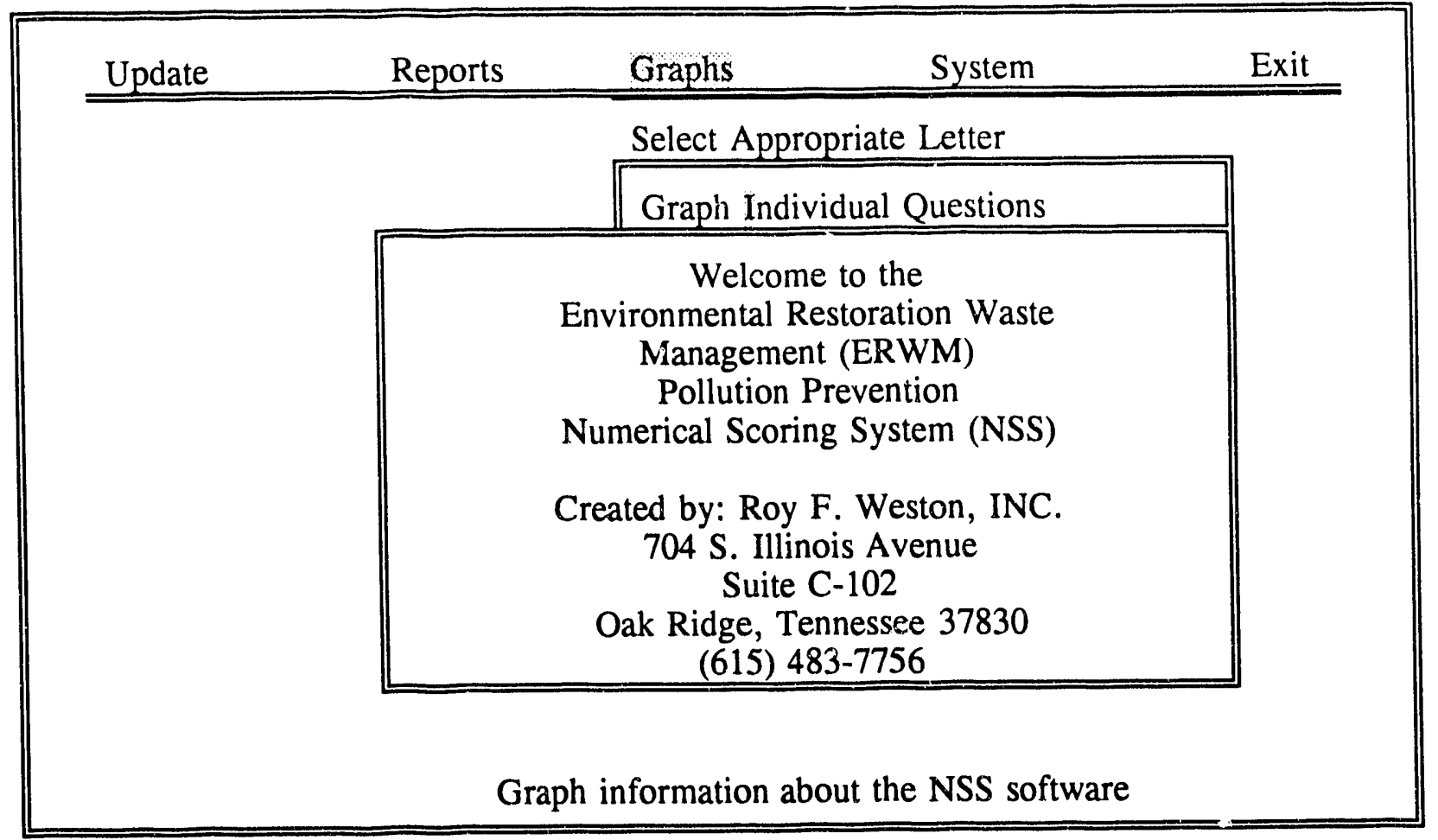

From the main menu, the user can choose to graph the responses to the questions asked by the program by selecting "Graph Individual Questions." At this choice the screen below appears. The user can choose what information is presented and whether the information is output on screen, to the printer, or in a file. "Cancel" returns the user to the main screen and "Continue" graphs the choice selected.

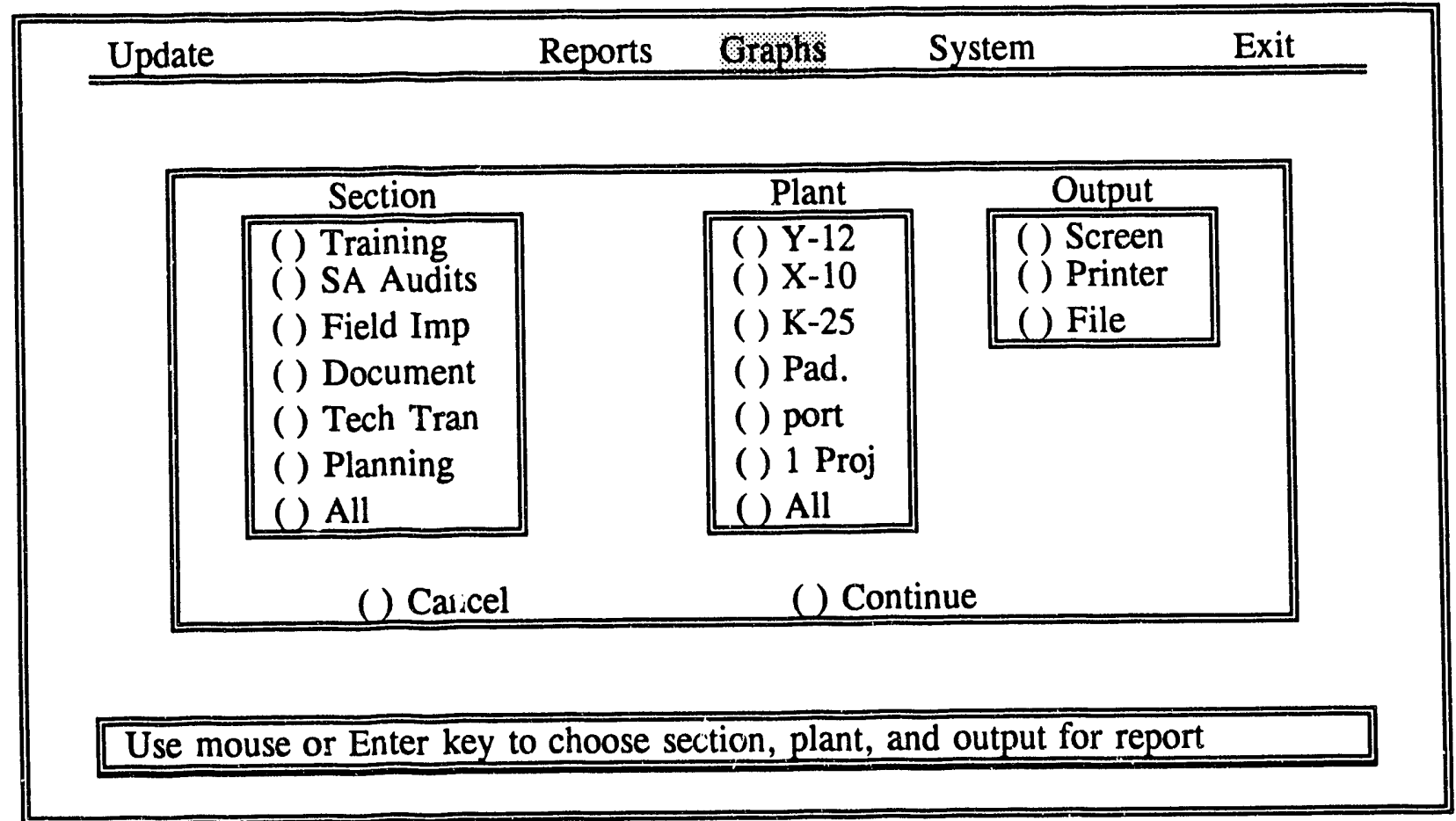




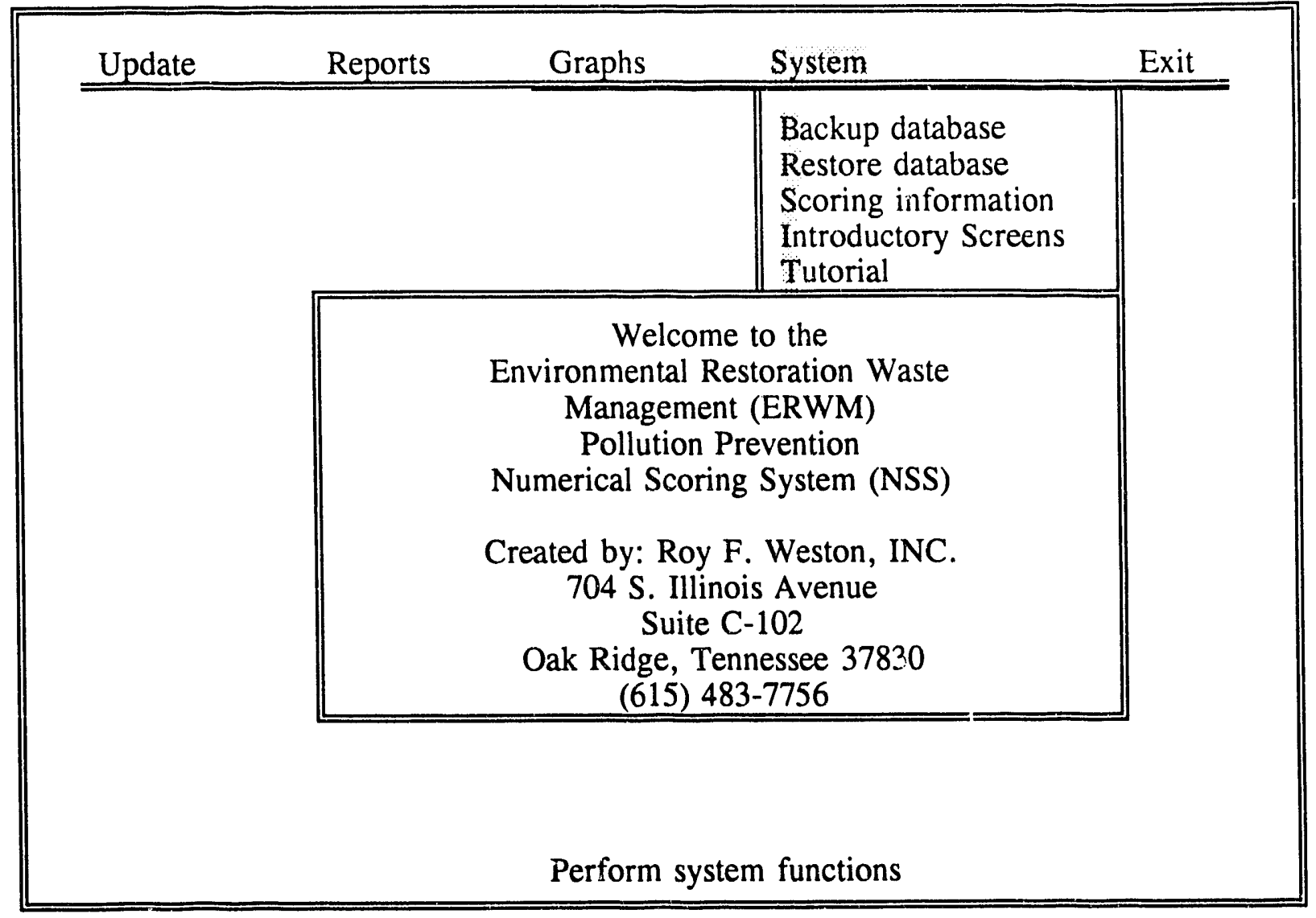

Under the "System" command on the main menu, the user can save the new information to the database by using the "Backup database" command. If the user decides that the information should not be included in the database, the user can revert to the original information by using the "Restore database" command. The user can change the weighting factors and the importance of the different parts of the scring by using the "Scoring information" command. If the user decides that the startup screel.. unnecessary, the user can toggle the screen off by pressing the "Information Screens" command. The "Tutorial" will be implemented in future tasks. 


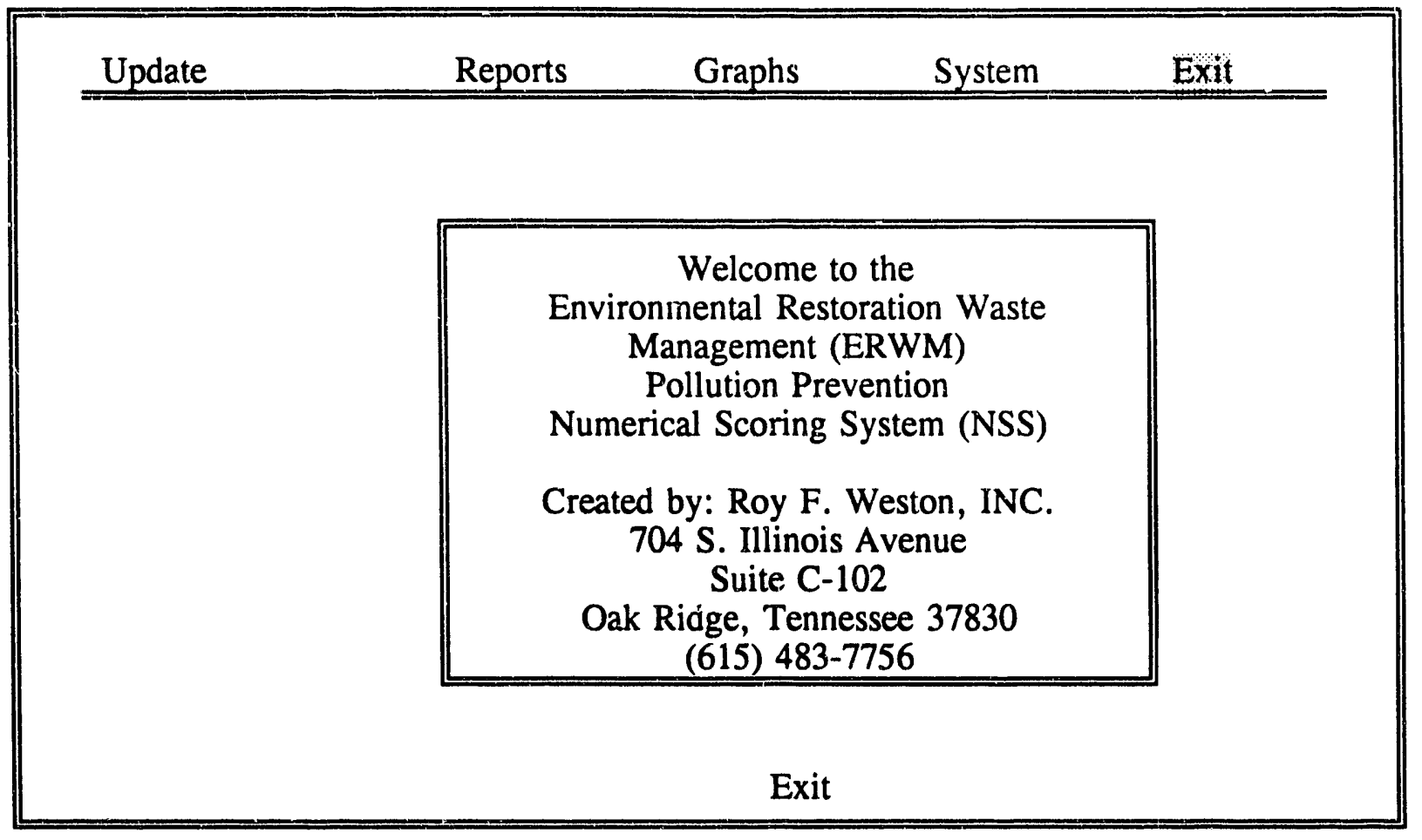

The "Exit" comrnand returns the user to the operating system. 


\section{DISTRIBUTION}

1. K. W. Cook

2. D. G. Cope

3. M. F. P. DeLozier

4. J. T. Grumski

5. B. L. Kimmel

6. B. E. Phifer

7. T. D. Taylor

8. Central Research Library

9-13. ER Document Management Center

14. ORNL Laboratory Records

15. E. J. Powell, DOE Oak Ridge Field Office, P. O. Box 2001, Oak Ridge, TN 37831-8541

16-17. R. L. Nace, Branch Chief, Nonenrichment Facilities, Oak Ridge Program Division, Office of Eastern Area Programs, Office of Environmental Restoration, EM-423, Trevion 2, U.S. Department of Energy, Washington, DC 20585

18-19. H. M. Thron, Chief, Enrichment Facilities, Oak Ridge Program Division, Office of Eastern Area Programs, Office of Environmental Restoration, EM-423, Trevion 2, U.S. Department of Energy, Washington, DC 20585

20-21. Office of Scientific and Technical Information, P.O. Box 62, Oak Ridge, TN 37831 

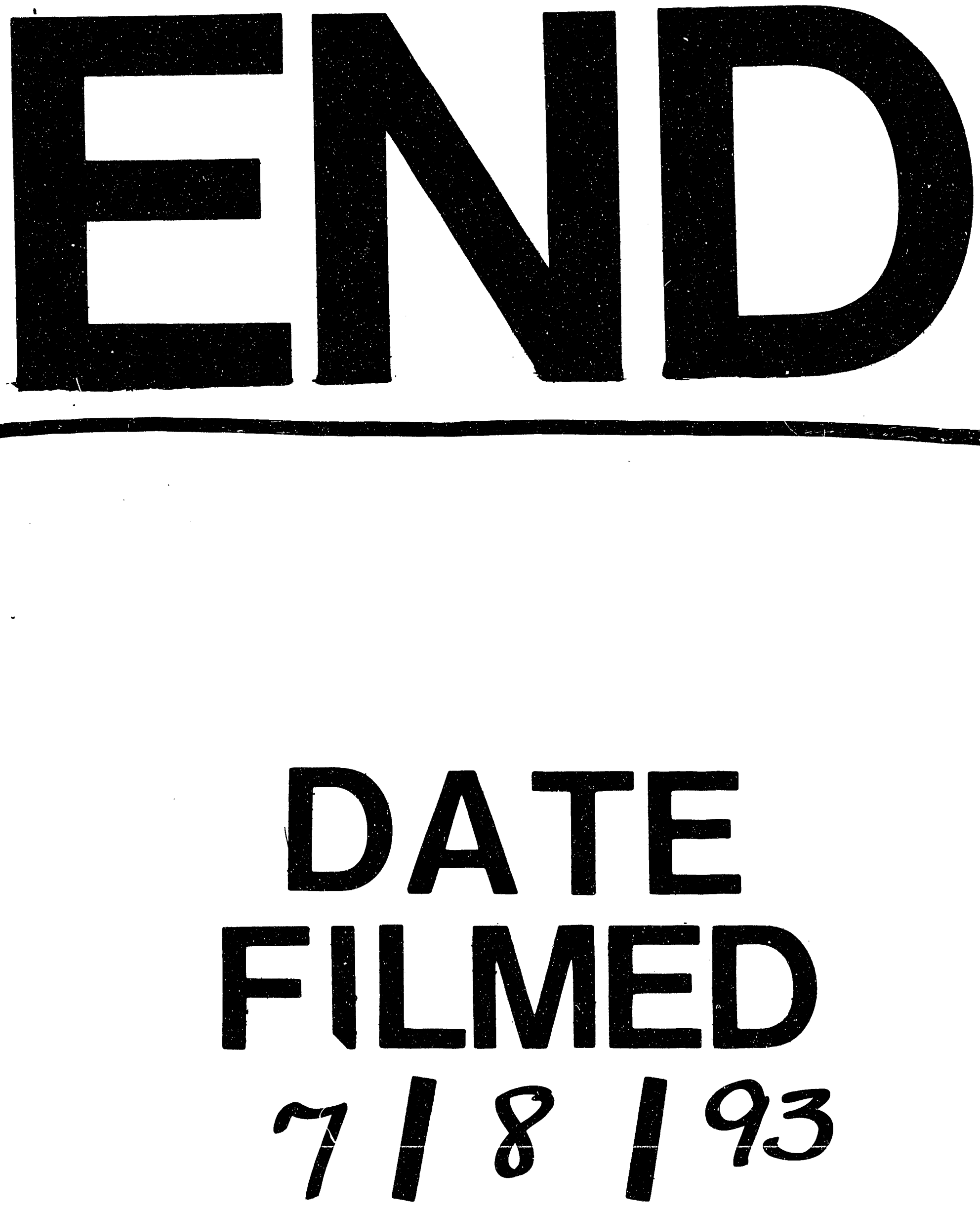
